\title{
Game changers in pediatric surgery
}

Volume 5 Issue 5 - 2016

Keywords: game changers, haemangiomas, long term chemotherapy, etio-pathogenesis

Abbreviations: IGICH, Indira Gandhi institute of child health; CIC, clean intermittent self catheterization; ET, empyema thoracis; VUR, vesico-ureteric reflux

\section{Case report}

The last few decades have witnessed tremendous advances in technology and research in all the fields of science. Medical science is no exception to this. With better understanding about the etio-pathogenesis and the natural history of several diseases, their management have also consequently changed. It is important to keep abreast with these changes for optimal management of our children. This article highlights some of the "Game changers" witnessed in the field of pediatric surgery in the last two decades that has a bearing for practicing Pediatricians.

\section{Management of infantile haemangioma}

Perhaps no other pediatric condition can match the U-turn in its management as the management of Inantile Hemangiomas. Some of them present as small single lesions in the trunk, which most of the treating clinicians are happy to advise a conservative wait $\&$ watch approach with the chances of spontaneous involution very high.

The management of large disfiguring proliferative haemangiomas especially those in the head and neck region was always consternating to the treating pediatrician as they posed real danger of damaging vital organs like the eyes.

It was by sheer serendipity that the effectiveness of Oral Propranolol in the management of infantile hemangiomas was discovered. LeauteLabreze $^{1}$ reported the rapid involution of a concomitant hemangioma when a few children were put on oral propranolol for other conditions. This report was quickly followed by more trials and now, propranolol has become the main stay in the treatment of infantile hemangiomas.

After initial clinical examination and cardio-vascular assessment, propranolol can be started under clinical observation with a dosage ranging from $1-4 \mathrm{mg} / \mathrm{kg}$ body weight per day. ${ }^{2}$ Post initiation, side effects of the drug namely bradycardia, hypotension, hypoglycaemia needs to be monitored (Figure 1).

At Indira Gandhi Institute of Child Health (IGICH), we have had $87 \%$ success in infantile hemangiomas with very good response noted in 42 of the 48 children in whom oral Propranolol was tried. The other 6 requiired oral or local steroids.

Oral Propranolol, thus has brought the smile back on the faces not only of the parents, but also those of the Pediatricians.

\section{Management of lymphangioma}

The treatment of lymphangioma has steadily shifted from aggressive surgical excision to a more conservative approach in

\author{
Ramesh Santhanakrishnan,' Raghunath BV' \\ 'Professor \& Head of Pediatric Surgery, Indira Gandhi Institute \\ of Child Health, India \\ ${ }^{2}$ Associate Professor of Pediatric Surgery, Rajarajeshwari \\ Medical College, India
}

Correspondence: Ramesh Santhanakrishnan, Professor \& Head of Pediatric Surgery, Indira Gandhi Institute of Child Health, Bangalore, India, Email doctorsramesh@gmail.com

Received: July 13, 2016 | Published: November 04, 2016

suitable cases. Macroscystic variety of Lymphangiomas have been shown to respond well to injection of sclerosants. The current choice of sclerosants include Bleomycin, ${ }^{4}$ OK $432^{5}$ (Picibanil) (lyophilized mixture of group A Streptococcus pyogenes with antineoplastic activity) or tetracycline (Figure 2).

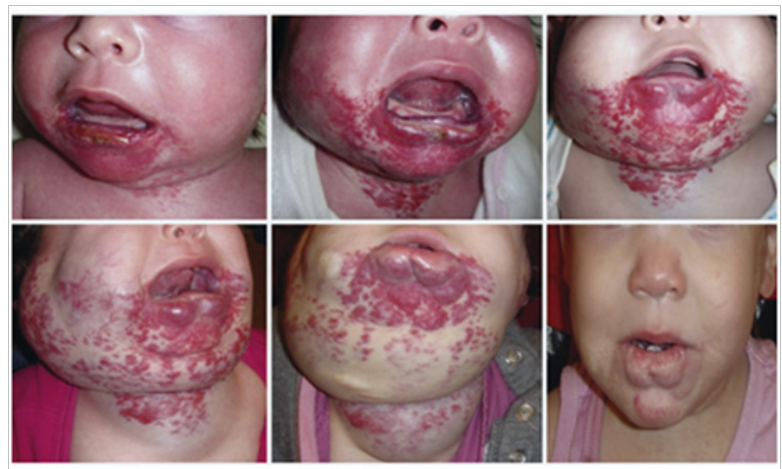

Figure I Serial photographs showing resolution of a cervico-facial hemangioma with Propranolol therapy. ${ }^{3}$

More than $80 \%$ of the macrocystic variants of lymphangioma respond to intralesional sclerotherapy, thereby avoiding potential complications related to surgery including damage to adjacent structures, wound infection, lymphatic leak, and recurrence etc. Usually, Bleomycin is injected at a dose of $0.3-0.6 \mathrm{mg} / \mathrm{kg}$ per dose at an interval of 2-6 weeks. The total dosage should not exceed $5 \mathrm{mg} /$ kg body weight. ${ }^{6}$ Management of Microcystic, mixed Lesions and lympho-vascular Malformations have remained a surgical challenge though and do still require extensive and multiple surgeries for treatment.

\section{Management of antenatally detected hydronephrosis}

There have been greater advances in technology related to radio diagnosis/ nuclear medicine and better understanding of the natural 
history of the various causes for fetal hydronephrosis. Consequently, the management has significantly changed.

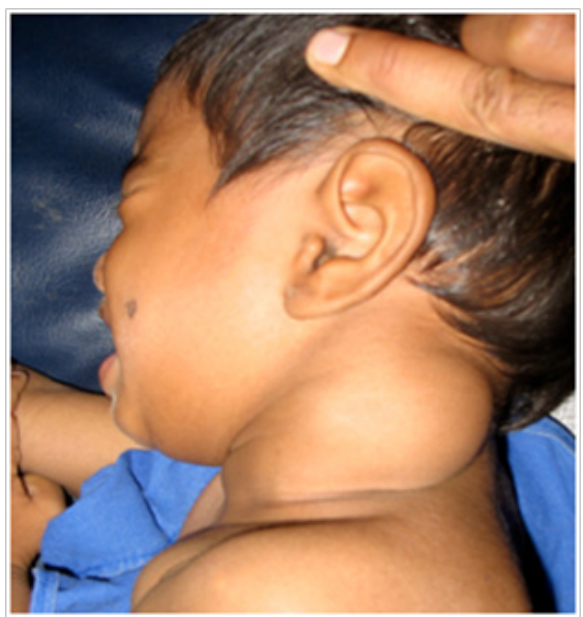

Figure 2 Child with Lymphangioma prior to injection.

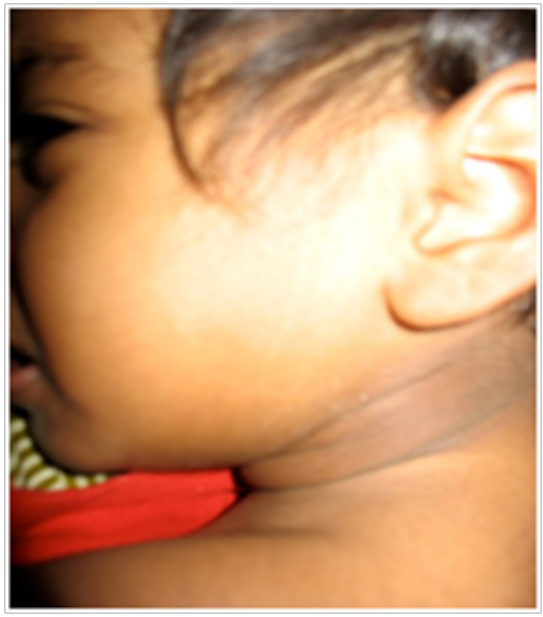

Figure 3 Post injection showing resolution.

Currently, nearly $85 \%$ of fetueses diagnosed to have hydronephrosis do not require any post natal intervention. However, they do require a thorough evaluation before choosing a conservative approach.

Termination of pregnancies for fetal hydronephross is irrational and has no scientific basis as almost all of them have the full potency to live and lead a normal life. Today, the exact aetiology for hydronephrosis can be diagnosed antenatally in a majority of the cases and hence proper referral and decision taken whether the child needs treatment or not and if required, whether antenatal or post natal. Parents can be properly prognosticated regarding the nature of the disease.

a. $41-88 \%$ of antenatally detected hydronephrosis is transient in nature and only requires masterly inactivity with proper parental guidance. $^{7}$

b. Only $10-30 \%$ of antenatally detected hydronephrosis have Pyeloureteric junction obstruction (PUJ-O), out of which few children require surgery as per the surgical criteria.

c. $10-20 \%$ of these children have Vesico-ureteric reflux (VUR), the treatment of which has become more and more conservative. With the introduction of STING (sub ureteral trans urethral injection) therapy, the need for surgery has been limited to very few children with high grade reflux. ${ }^{8}$

Surgery for Infantile Hydronephrosis is indicated only if there is a documenation of impaired perfusion, reduced function $(<35-40 \%)$ and an unequivocal obstruction to the outlflow on isotope renogram (DTPA/EC/MAG 3).

Infants with an obstructive curve, but with preserved function $(>40 \%)$ are kept on an observational approach with serial measurements of the renal dimensions on USG. Surgery is necessary only if the parenchymal thickness falls or if there is compensatory hypertrophy of the contralateral approach and a documented fall $>10 \%$ in the renal function on isotope renography.

\section{Vesico-ureteric reflux}

The management guidleines of VUR have been so steadily changing that the current view may be considered nearly diametrically opposite as compared to the view held two decades ago.

Currently there are many conflicting views and practices in the management of VUR. The indication for surgical interventions in the form of Ureteric Re-implantations is now shrunk to massive refluxes, solitary systems, failed treatments etc. However, some surgical enthusiasts have been pushing Laparoscopic or Vesicoscopic Reimplantation. But then, these are only alternatives to open surgery and not for conservative management options.

Cystoscopic Injection of Dextranomer Polymer with Hyalurnidase $\left(\right.$ Deflux $\left.{ }^{\circledR}\right)$ is useful in specific indications like lower grade persistent reflux etc. The case selection is an important determinant factor apart from the cost onsiderations.

Notwithstanding all the factors, the current consensus for the management of VUReflux is essentially conservative as a vast majority of them resolve by about 5 years of age. ${ }^{9}$ Circumcision is a useful adjunct in male children in bringing down the incidence of UTI in all ages. Despite all the controversies surrounding the role of antibiotics, the general trend currently is to give oral prophylactic antibiotics in the first one to two years of age as the infant Kidney is more vulnerable to scarring than in older children. From third year onwards, it is optional. The management for VUR in children has steadily shifted towards conservative mamagement for the vast majority and surgical intervention reserved only to a small group of children (Table 1).

Table I IGICH experience

\begin{tabular}{lll}
\hline & Operative & Conservative \\
\hline $2006-2010$ & 162 & 58 \\
$2011-2014$ & 72 & 102 \\
2015 & 6 & 32
\end{tabular}

This data self explains the decreasing role of Surgery in the management of Vesico-ureteric reflux.

\section{Management of neurogenic bladder}

Children with neurogenic bladder are usually put on long term clean intermittent self catheterization (CIC). This is usually associated with pain (especially in a sensate urethra) and has a significant non compliance rate. Mitrofanoff procedure: (involves the creation of an intermittent, self catheterizable, continent channel, using Appendix as the conduit). The stoma is usually created in the anterior abdominal wall at the level of umbilicus or in the lower abdomen and is usually inconspicuous. This has revolutionized the concept of CIC as it has 
a better compliance rate due to easy accessibility, absence of pain. ${ }^{9}$ The concept of Clean Intermittent Catheterisation as an adjunct to the other measures for continence has found widespread acceptance even in the various social strata of our country.

\section{Management of chronic constipation}

Children with chronic constipation due to spinal problems, neglected functional constipation etc. are put on long term bowel washes, usually associated with problems like difficulty in self catheterization, poor social acceptance. The MACE procedure (Malone ante grade continent enema) involves creation of a self catheterizable, continent conduit over the anterior abdominal wall, usually using the Appendix. The stoma is usually created in the lower abdomen and is usually inconspicuous. This has better acceptability and compliance rates due to absence of pain and the improved self esteem for the children.

\section{Chemoports}

Children with malignancies are usually put on long term chemotherapy. This involves multiple venous pricks, finally resulting in non-availability. The use of Chemoports has circumvented this problem. It involves placement of a central venous catheter which is connected to a specially designed implantable device, placed in the sub cutaneous region. This can be pricked multiple number of times for intra vascular access. The entire unit can last till the completion of chemotherapy and can then be removed, thereby avoiding the complications related to multiple peripheral venous pricks. We, at IGICH, have used chemoports in $>300$ children so far with favourable results. Apart from Pediatric solid tunours, we have also placed in a significant number of children with haematologic malignancies.

\section{Pneumatic reduction of intussusception ${ }^{10}$}

Many methods have been used for the treatment of Ileo-colic intussusception including Hydrostatic reduction, Barium reduction, Surgical reduction. Pneumatic reduction is now being more commonly used which involves instillation of air through a Foley's catheter into the rectum, with pressure monitoring. A real time quick reduction of the intussusception can be seen under fluoroscopy.

\section{Use of fibrinolytics in empyema}

The management of empyema thoracis (ET) has consisted of administration of systemic antibiotics, with observation, thoracocentesis, insertion of a chest tube, or decortication. The use of intrapleural enzymatic agents for dissolution of ET was first described by Tillett and Sherry ${ }^{10}$ in 1949. Streptokinase and Urokinase are being used effectively. Fibrinolytics decreases empyema viscosity and dissolves loculations within the pleural space and thereby facilitates treatment. ${ }^{12}$ The success rate claimed with this treatment ranges from $60-90 \% .^{12,13}$ This helps to avoid the potential complications related to decortication.

\section{Conclusion}

With better understanding of the disease processes in Children, the treatment options of many of the 'surgical' conditions have dramatically altered our approach. The Pediatric Surgeons are now in a much better level to offer judicious conservatism than ever before in the interest of the child. We are happy to spare our scalpels and offer much more 'baby-friendly' treatment options to the little children entrusted to our care.

\section{Acknowledgments}

None.

\section{Conflicts of interest}

Authors declare that there is no conflict of interest.

\section{References}

1. Léauté-Labrèze $\mathrm{C}$, Dumas de la Roque $\mathrm{E}$, Hubiche $\mathrm{T}$, et al Propranolol for severe hemangiomas of infancy. $N$ Engl J Med. 2008;358(24):2649-2651.

2. Gunturi N, Ramgopal S, Balagopal S, et al. Propranolol Therapy for Infantile Hemangioma. Indian Pediatr. 2013;50(3):307-313.

3. Arnold GC, Scott A, Thomas MK, et al. Pediatric Surgery. Philadelphia: Saunders Elsevier, USA; 2006

4. Yura J, Hashimoto T, Tsuruga N, et al. Bleomycin treatment for cystic hygroma in children. Nihon Geka Hokan. 1977;46(5):607-614.

5. Ogita S, Tsuto T, Nakamura K, et al. OK-432 therapy in 64 patients with lymphangioma. J Pediatr Surg. 1994;29(6):784-785.

6. Sung MW, Chang SO, Choi JH, et al. Bleomycin sclerotherapy in patients with congenital and lymphatic malformation in the head and neck. Am J Otolaryngol. 1995;16(4):236-241.

7. Nguyen HT, Herndon CD, Cooper C, et al. The society for fetal urology consensus statement on the evaluation and management of antenatal hydronephrosis. J Pediatr Urol. 2010;6(3):212-231.

8. Capozza N, Lais A, Matarazzo E, et al. Treatment of vesico-ureteric reflux: a new algorithm based on parental preference. BJU Int. 2003;92(3):285-288.

9. Schwab CW, Wu HY, Selman H, et al. Spontaneous Resolution of Vesicoureteral Reflux: A 15-Year Perspective. J Urol. 2002;168(6):2594-2599.

10. M Stein, D J Alton, Daneman A. Pneumatic reduction of intussusception: 5-year experience. Radiology. 1992;183(3):681-684.

11. Tillett WS, Sherry S. Effect in patients of streptococcal fibrinolysin (streptokinase) and streptococcal desoxyribonuclease on fibrinous, purulent, and sanguinous exudations. J Clin Invest. 1949;28(1):173-186.

12. Thomas R, Fabrizio F, Randolph MK, et al. Intrapleural Fibrinolytics in Management of Empyema Thoracis. Chest. 1996;110:102-106.

13. Moulton JS, Benkert RE, Weisiger KH, et al. Treatment of complicated pleural fluid collections with image-guided drainage and intracavitary urokinase. Chest. 1995;108(5):1252-1262. 